\title{
Gangliocytoma with Immature Neuronal Cell Elements in the Pituitary of a Rat
}

\author{
Yoshimasa OKAZAKI, Osamu KATSUTA, Mitsue YOKOYAMA, Yumi WAKO, Yasuhiko YAMAGISHI, and
} Minoru TSUCHITANI

Mitsubishi Chemical Safety Institute Ltd., 14 Sunayama, Hasaki-machi, Kashima-gun, Ibaraki 314-02, Japan

(Received 24 March 1997/Accepted 19 May 1997)

ABSTRACT. A spontaneous pituitary gangliocytoma with abundant, immature neuronal cell elements was found incidentally in a 109-weekold female Fischer 344 rat. The pituitary parenchyma was largely occupied by a tumor nodule with necrotic and hemorrhagic foci and cyst. The tumor was composed of mature ganglion-like (M) cells, small immature ganglion (I) cells and transitional (T) cells, with a fibrillar matrix. The I and T cells were intermingled with the M cells or were arranged in compact clusters, in which the I cells formed perivascular rosette-like structures, sometimes with mitotic figures. Immunohistochemically, all types of tumor cells were positive for neuron-specific enolase, and only the $\mathrm{M}$ cells was positive for chromogranin A. This result may be correlated with the degree of cytodifferentiation. - KEY WORDS: gangliocytoma, immature neuronal cell, rat pituitary.

Gangliocytomas and ganglioneuromas are composed of mature ganglion cells with a minor component of supportive, non-neoplastic glial cells [2,9]. In rats, spontaneous neuronal tumors containing mature ganglion cells are occasionally found in the adrenal medulla $[5,6,11,12]$. However, neuronal tumors are extremely rare in other organs and tissues, including the pituitary [8] and the intracranial ganglion [5]. Ganglioneuromas of the pituitary and cranial ganglion were entirely composed of mature ganglion-like cells $[5,8]$. This paper describes a spontaneous gangliocytoma in the pituitary of a rat, with abundant immature ganglion cells.

A 109-week-old female Fischer 344 rat, which had been employed in the low-dose group in a carcinogenicity study, was sacrificed at the end of the study. The animal showed no clinical signs during the study. The carcinogenic effects of the test material were not detected in the pituitary or other organs. Animals were purchased from a commercial breeder (Charles River Co. Japan Inc., Japan) at 4 weeks of age. Pairs of animals were housed in polycarbonate cages at a room temperature of $20-25^{\circ} \mathrm{C}$, humidity of $40-70 \%$, and lighting for $12 \mathrm{hrs}$ a day in the barrier system. The animals were fed a sterilized standard laboratory diet (CRF1, Oriental Yeast Co., Ltd., Japan) and water ad libitum.

At necropsy, a cyst measuring $5 \mathrm{~mm}$ in diameter was found in the pituitary of this animal. Tissue specimens of all organs and tissues were fixed in $10 \%$ neutral buffered formalin, and processed in paraffin wax by routine methods. Thin sections of the pituitary were stained with hematoxylin and eosin (HE), and cresyl violet (Nissl stain). Additionally, they were immunostained with a labelled streptavidin-biotin method (LSAB Kit, DAKO Japan Co., Ltd., Japan) using the following antibodies (DAKO Japan Co., Ltd.); anti-cow S-100 protein (1:500 in dilution), anti-human neurofilament protein (NF, 1:200 in dilution), anti-cow glial fibrillary acidic protein (GFAP, prediluted), anti-swine vimentin (prediluted), anti-human synaptophysin (prediluted), antihuman chromogranin A (prediluted), anti-human neuron-specific enolase (NSE, prediluted) antibodies. Normal rat brain and spinal ganglia were used as the control. The immunostained sections were lightly counterstained with methyl green.

The pituitary parenchyma was largely occupied by the tumor nodule and cyst (Fig. 1). The anterior lobe was compressed at the periphery of the pituitary. The nodule contacted the anterior lobe without capsule. The nodule was also close to the cyst. The cyst was lined by singlelayered cuboidal or flattened epithelium, some of which had cilia. Therefore, it was considered that the cyst was derived from Rathke's pouch. Necrotic and hemorrhagic foci were frequently seen in the nodule. The intermediate and posterior lobes were included in the nodule and could not be recognized.

In the nodule, a large number of ganglion- or neuronlike cells were widely present without the orderly

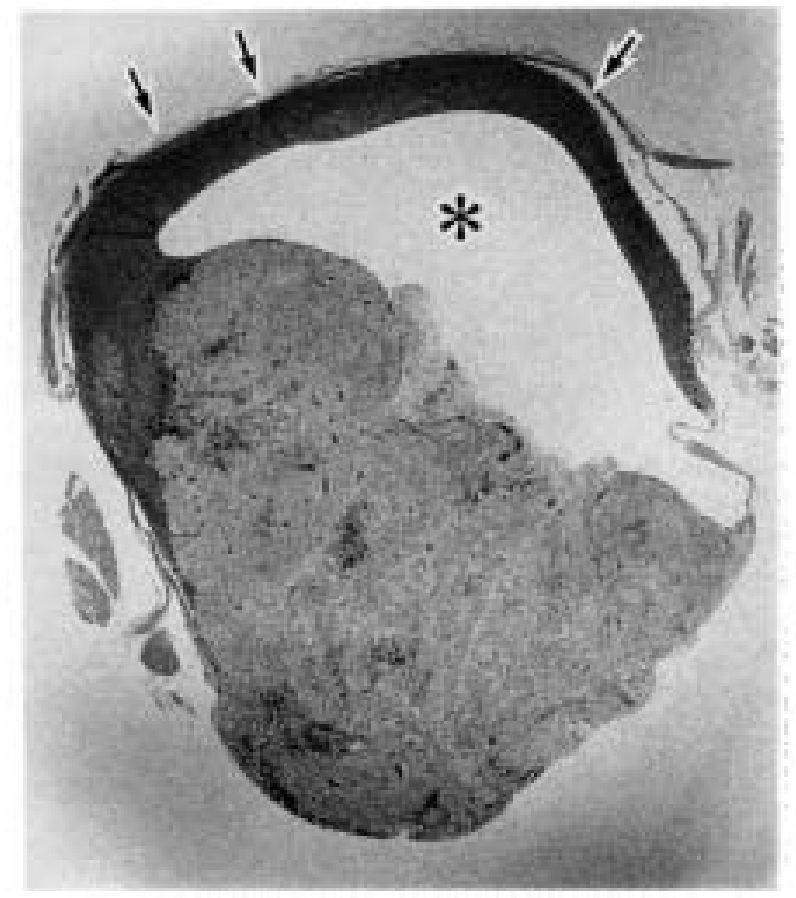

Fig. 1. Pituitary with gangliocytoma and cyst (asterisk). The anterior lobe is compressed at the periphery (arrows). HE stain. $\times 15$. 


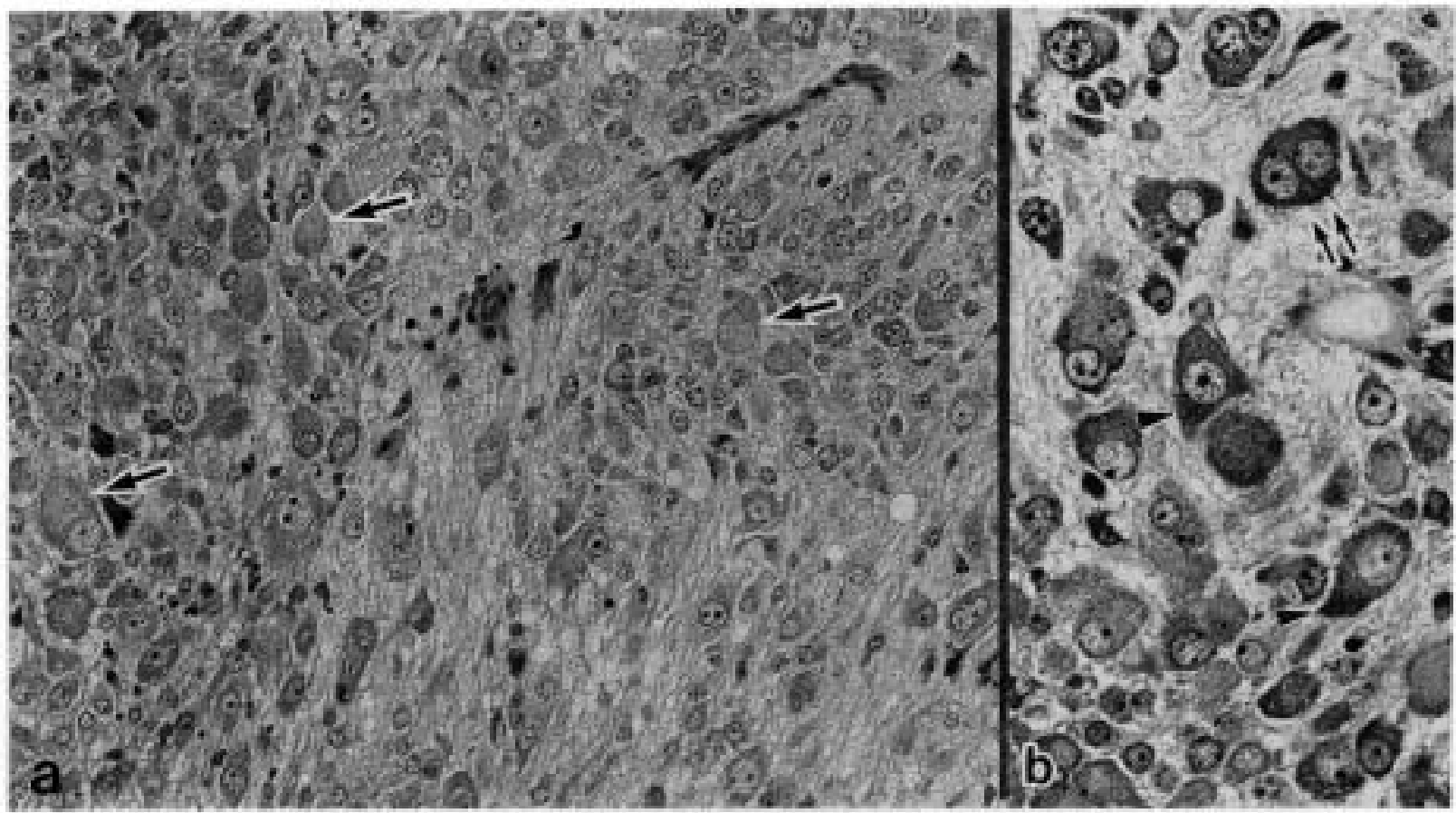

Fig. 2. a) Pyramidal-shaped neuron-like tumor cells in the nodular lesion. These show eccentrically located large, round, pale nuclei with one or two prominent nucleoli. No satellite cells are seen. The background parenchyma is composed of a loosely arranged fibrillar matrix. Note the pale staining area adjacent to the nucleus (arrows). HE stain. $\times 220$. b) In some neuron-like tumor cells, Nissl substance is demonstrated at the margin of the cytoplasm (arrowheads). Binucleated cells are occasionally observed (doublearrow). Nissl stain. $\times 500$.

distribution and with a loosely arranged fibrillar matrix (Fig. 2a). The ganglion-like cells were pyramidal in shape, which contain eccentrically located large, round, pale nuclei with one or two prominent nucleoli (Fig. 2a). Binucleated cells were also observed (Fig. 2b). The cytoplasm was abundant and eosinophilic to weakly basophilic. In some of the large ganglion-like cells, a pale staining area was seen adjacent to the nucleus (Fig. 2a), and Nissl substance was demonstrated at the margin in the cytoplasm (Fig. 2b). Satellite cells were absent.

Short fusiform or wedge-shaped small cells were also present in the nodule. They had small, round, relatively pale nuclei and scant basophilic cytoplasm. Nissl substance was inconspicuous. These small cells were intermingled with ganglion-like cells or were arranged in compact clusters (Fig. 3). Mitotic figures were sometimes observed in the small cells. Transitional cells between the large ganglionlike cells and the small cells were abundantly present throughout the nodule. The quantity of Nissl substance was various among the transitional cells. Although no distinctive rosette formation was observed, perivascular rosette-like structures were occasionally found (Fig. 3).

All types of tumor cells were positive for NSE (Fig. 4), but the staining intensity varied among the same types of cells. The apparent ganglion-like cells showed positive reactivity for chromogranin A (Fig. 5). The immunoreactivity for small and transitional types of cells

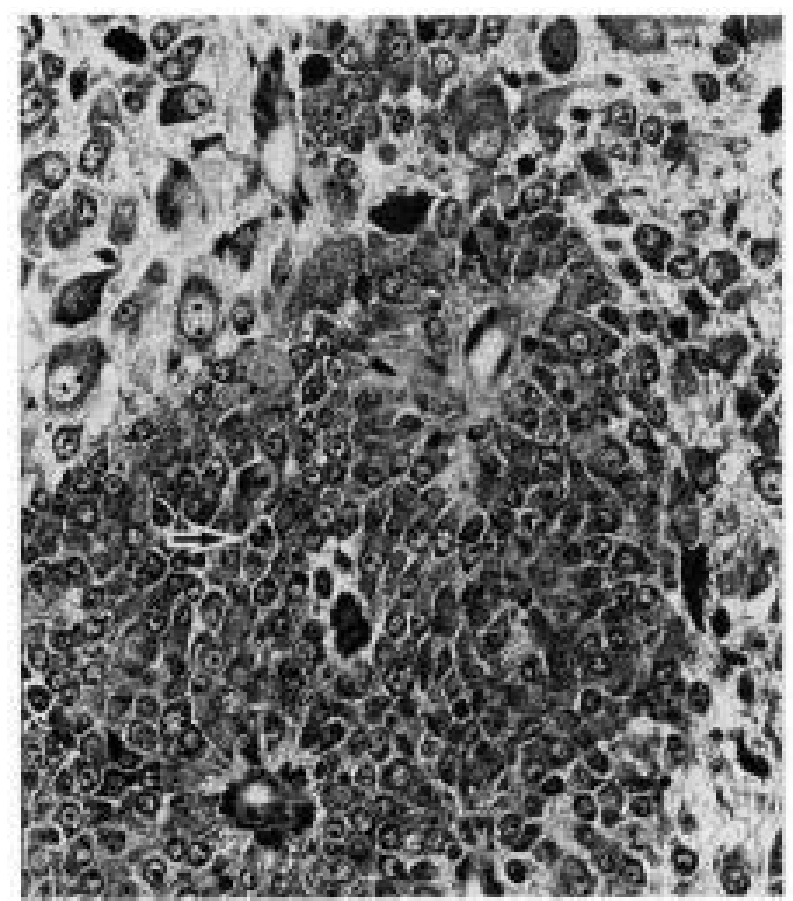

Fig. 3. A compact cluster of short fusiform or wedge-shaped small tumor cells surrounding the capillaries. Mitotic figure is seen (arrow). Nissl stain. $\times 390$. 


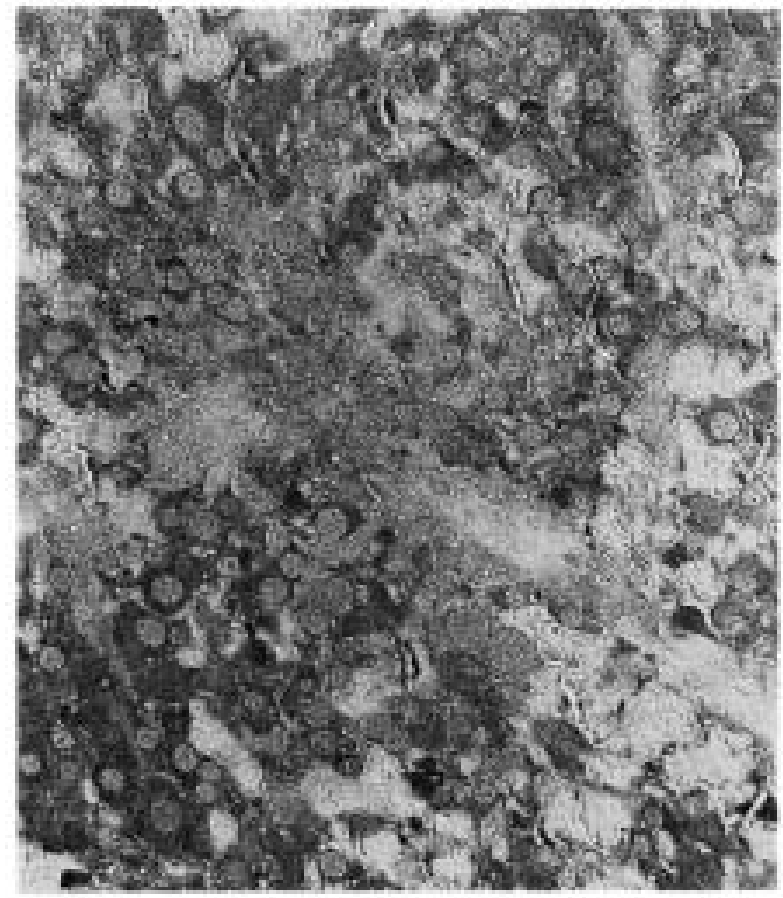

Fig. 4. All types of tumor cells showed immunoreactivity to anti-NSE antibody. In this field, ganglion-like cells and transitional cells are abundant. LSAB method, methyl green counterstain. $\times 350$.

was negative or very weak for chromogranin A. The other antibodies showed negative immunoreactivity in the tumor cells.

The tumor did not invade the extra-pituitary region, and there were no neuronal tumors present in other organs or tissues, including cranial ganglia.

In laboratory animals, neuronal tumors are classified into four categories, namely, gangliocytomas, gangliogliomas, ganglioneuroblastomas, and neuroblastomas [13]. Each tumor is defined as follows: neuroblastomas are composed of small undifferentiated cells with characteristic rosettes; gangliocytomas contain more differentiated neuronal elements, and ganglioneuromas are the peripheral counterpart of the gangliocytomas; gangliogliomas involve the neoplastic glial elements in addition to neoplastic neuronal cells [9], and ganglioneuroblastomas have all intermediate levels of differentiation between pure neuroblastomas and ganglioneuromas [3].

In rats, except for the adrenals, only a few cases of mature ganglioneuromas have been reported in the pituitary [8] or the cranial ganglion [5]. However, to our knowledge, there is no report of pituitary gangliocytoma containing a large number of immature neuronal cell elements.

In gangliocytomas (ganglioneuromas), some unique findings such as a pale staining area adjacent to the nucleus [12], marginal demonstration of Nissl substance [2, 12], and binucleated appearance $[2,7]$ are frequently observed. These are not found in normal neuronal cells. Also, Nissl

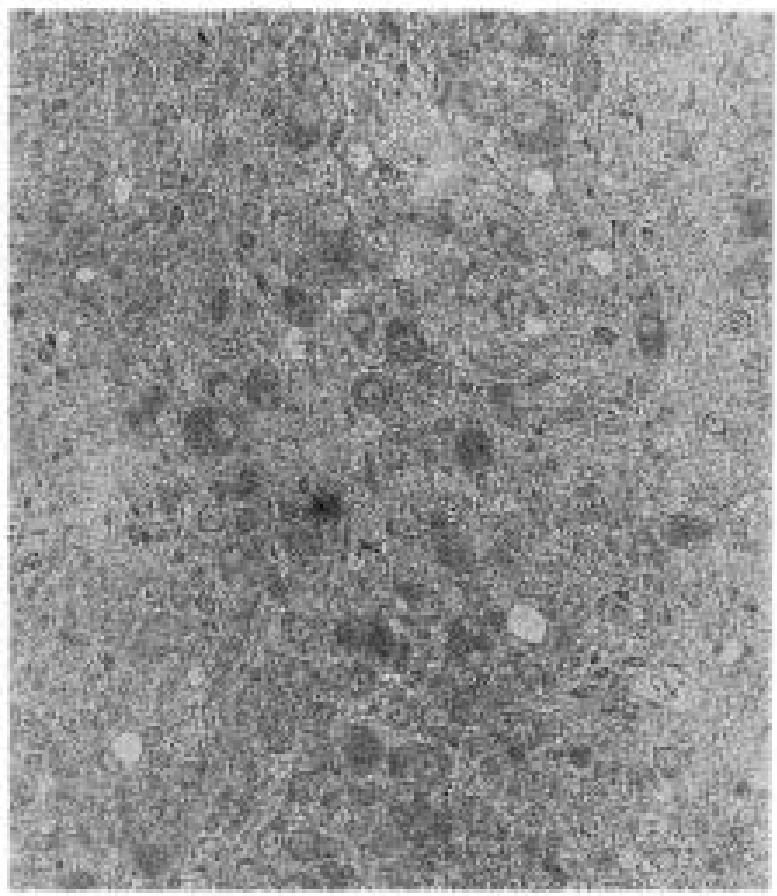

Fig. 5. Ganglion-like tumor cells with immunoreactivity to anti-chromogranin A antibody. The small and transitional cells show negative or very weak reactivity. LSAB method, methyl green counterstain. $\times 216$.

substance is often meager and satellite cells are usually absent in ganglioneuroma [7]. In the human cases, mitotically active neoplastic cells are not seen, although smaller neurons are sometimes admixed [2]. All of the findings described above were observed in the present case. In addition, necrotic and hemorrhagic foci were seen in the nodule. Therefore, the present case may differ from typical gangliocytomas.

NSE is considered as one of the most useful markers for the diagnosis of neuroblastomas and other neuronal tumors [16]. In the present case, all types of tumor cells, such as ganglion-like cells, small immature cells and their intermediate cells, were positive for NSE. This result may suggest that our case is neuronal in origin, although the staining specificity of NSE in rodents is not established. Chromogranin $\mathrm{A}$ is one of the acidic glycoproteins and is contained in the neurosecretory granules of the adrenal medullary parenchymal cells [15]. The identical glycoprotein is present in other endocrine tissues, including sympathetic ganglia and specific neurons [15]. Positive immunoreactivity to anti-chromogranin A antibody was observed in ganglion-like cells, while small and transitional cells showed negative or very weak reactivity. Therefore, the detection of this glycoprotein in our case might be correlated with the degree of cytodifferentiation.

Although NF is highly specific for neurons and neuronal tumors in humans [1], it was not demonstrated in any tumor cells of the present case. Negative results have been 
reported in some human cases of gangliogliomas [4] and a canine case of gangliocytoma [10]. The development of filament protein might be insufficient to detect with the antibody used in the present study, or the negative reactivity might be due to tissue processing limitations [14]. In our case, synaptophysin was also negative. The localization of synaptophysin in tumor cells is apparently more indicative of endocrine cell origin than that of chromogranin [15], but the cause of our negative result remains unknown.

The negative results for S-100 protein and GFAP suggest that this tumor was composed of a single cell type without glial or other mesenchymal elements.

According to several findings described above, we diagnosed this tumor as gangliocytoma of the pituitary, although the exact site of origin was unclear. The most interesting finding is the admixture of abundant, immature neuronal cell elements with mitotic activity. This feature is reminiscent of ganglioneuroblastomas.

ACKNOWLEDGMENTS. We thank Mr. Takayoshi Ito, and Ms. Kiyomi Okazaki for technical assistance.

\section{REFERENCES}

1. Barwick, K. W. 1990. pp. 4.1-4.15. In: Atlas of Diagnostic Immunohistopathology (True, L. D. ed.), J. B. Lippincott Company, Philadelphia.

2. Burger, P. C. and Scheithauer, B. W. 1994. pp. 163-191. In: Atlas of Tumor Pathology, Tumors of the Central Nervous System, 3rd ser. (Burger, P. C. and Scheithauer, B. W. eds.), Armed Forces Inst. Pathol., Washington, D. C.

3. DeLellis, R. A. 1989. pp. 1205-1276. In: Robbins Pathologic Basis of Disease, 4th ed. (Cotran, R. S., Kumar, V., and Robbins, S. L. eds.), W. B. Saunders Company, Philadelphia.
4. Diepholder, H. M., Schwechheimer, K., Mohadjer, M., Knoth, R., and Volk, B. 1991. Cancer 68: 2192-2201.

5. Fitzgerald, J. E., Schardein, J. L., and Kurtz, S. M. 1974. J. Natl. Cancer Inst. 52: 265-273.

6. Glaister, J. R., Samuels, D. M., and Tucker, M. J. 1977. Lab. Anim. 11: 35-37.

7. Harkin, J. C. and Reed, R. J. 1969. pp. 137-150. In: Atlas of Tumor Pathology, Tumors of the Peripheral Nervous System, 2nd ser. (Harkin, J. C. and Reed, R. J. eds.), Armed Forces Inst. Pathol., Washington, D. C.

8. MacKenzie, W. F. and Boorman, G. A. 1990. pp. 485-500. In: Pathology of the Fischer Rat (Boorman, G. A., Eustis, S. L., Elwell, M. R., Montgomery, C. A. Jr., and MacKenzie, W. F. eds.), Academic Press, San Diego.

9. Morris, J. H. 1989. pp. 1385-1449. In: Robbins Pathologic Basis of Disease, 4th ed. (Cotran, R. S., Kumar, V., and Robbins, S. L. eds.), W. B. Saunders Company, Philadelphia.

10. Nyska, A., Shamir, M. H., Harmelin, A., Sandbank, J., and Waner, T. 1995. Vet. Pathol. 32: 190-192.

11. Reznik, G. and Ward, J. M. 1983. pp. 30-34. In: Monographs on Pathology of Laboratory Animals, Endocrine System (Jones, T. C., Mohr, U., and Hunt, R. D. eds.), SpringerVerlag, Berlin.

12. Reznik, G., Ward, J. M., and Reznik-Schüller, H. 1980. Vet. Pathol. 17: 614-621.

13. Solleveld, H. A., Bigner, S. H., Boorman, G. A., and Bigner, D. D. 1990. pp. 485-504. In: Atlas of Tumor Pathology of the Fischer Rat (Stinson, S. F., Schuller, H. M., and Reznik, G. K. eds.), CRC Press, Florida.

14. Trojanowski, J. Q., Lee, V. M.-Y., and Schlaepfer, W. W. 1984. Hum. Pathol. 15: 248-257.

15. True, L. D. 1990. pp. 11.1-11.27. In: Atlas of Diagnostic Immunohistopathology (True, L. D. ed.), J. B. Lippincott Company, Philadelphia.

16. Tsokos, M., Linnoila, R. I., Chandra, R. S., and Triche, T. J. 1984. Hum. Pathol. 15: 575-584. 